Article

\title{
Social Perspectives in Digital Business Models of Railway Enterprises
}

\author{
Adam Jabłoński *(D) and Marek Jabłoński * \\ Institute of Management and Quality, WSB University in Poznan, Powstańców Wielkopolskich 5, \\ 61-895 Poznan, Poland \\ * Correspondence: adam.jablonski@ottima-plus.com.pl (A.J.); marek.jablonski@ottima-plus.com.pl (M.J.)
}

Received: 23 October 2020; Accepted: 2 December 2020; Published: 5 December 2020

check for updates

\begin{abstract}
The digital transformation of business models is a process which helps traditional business solutions reach new functionalities through innovative technologies. Digital transformation is now crucial to the development of the rail transport sector. The main rail market entities are railway undertakings, infrastructure managers, entities in charge of maintenance, or certification bodies. Digitalization creates new opportunities to shape the business ecosystem in the rail transport sector. The aim of the research is to identify and indicate key social perspectives related to the development of digital business models functioning in railway enterprises. Technological aspects and relational determinants related to the strong mutual cooperation required between railway undertakings and infrastructure managers have particular significance in this context. In this approach, the digitalization of processes is important. The approach also reveals a significant process of business model socialization, which is conceptualized and operationalized through the evolution of social factors based on digital transformation.
\end{abstract}

Keywords: digital economy; social perspective; social business model; railway sector

\section{Introduction}

The digital evolution of business models from the perspective of economy sectors hitherto regarded as traditional is currently in progress. Processes based on transforming analog business formulas into the digitalization of entire value chains, as well as selected fragments, are taking place. This is achieved due to the fact that digitalization is favorable to phenomena such as expanding the scope of activities, increasing opportunities to create added value from services provided through the use of modern technological solutions, shortening the time of process implementation, better communication and an increased and related service recipients and stakeholders interested in their results. Digitalization is a factor which is responsible for the modern creation of business models in the context of their innovations [1].

In the relevant literature there is an increasing amount of interest in the transformation processes of business models from traditional ones to those based on digitalization. J. Reis defines digital transformation as the use of new digital technologies that enable significant business improvements and affect all aspects of customers' lives. In the relevant literature, there are numerous classifications of concepts related to digital transformation. Reis et al. indicate three key areas: technological, organizational, and social [2].

It should be noted that the concept of digital transformation is highly complex and widely interpreted. It is related, inter alia, to many phrases which describe this verbal construction. For example, Fadwa Zaoui and Nissrine Souissi conducted bibliographic research, the result of which was the determination of 156 phases of the semantic categorization of the concept of digital transformation [3]. Digital transformation is associated, especially in terms of management mechanisms, with business models, strategies, business processes and projects, and has become a strategic imperative on leadership agendas [4]. Many enterprises 
address issues related to digital transformation to strategies, organizational structures, operations, and culture [5]. Digitization refers to the transformation of information and processes from analog to digital ones in a technical context [6]. Digitalization is treated as a technical process based on the transformation of traditional formulas of action into those supported by digital solutions [7].

Digitalization makes physical products programmable, identifiable, addressable, memorable, communicable, and reasonable [8]. Digital transformation includes changes that digital technologies can trigger in an organization's business model, which may be related to the change of products, organizational structures, or process automation [9].

Digitalization refers to taking digital opportunities into account. Digital transformation is defined as the process used to restructure economies, institutions, and society in systemic terms [10]. Digital transformation refers to processes, the purpose of which is to improve the organization by creating changes in its areas through a combination of information, computing, and communication technologies [11]. Digital transformation is developing strongly in many sectors of the economy and industry, the result of which is a large technological change covering the key areas of creating business principles and relationships in complex value chains. It encompasses several phases: digitization, virtualization, connectedness, and autonomization [12].

Digital transformation is also associated with new business models related to management concepts, such as the sharing economy [13], the artificial intelligence economy [14], the Internet of Things [15], and the Big Data economy [16]. Digital innovation is a way for new organizations to use digital technology to gain a competitive advantage [17].

D. Schallmo and C.A. Williams indicate a digital transformation background, which includes the networking of actors (such as customers and businesses in all value-added chain segments) and the operation of new technologies [18]. Digital transformation requires skills related to the acquisition and transformation of data, their analysis and application, and relates to enterprises, their business models, products, relationships, processes, etc. Other approaches to the identification of digital transformation were presented by [19], who highlighted the aspect of value chain reconfiguration, as well as [20], who identifies the assumptions of digitalization at strategic and tactical levels. In turn [21] base their considerations on the role of networked systems in the procedure of the digital conversion of business models. When it comes to operationalization, digital transformation may refer to all components of the ontological business model. The traditional components of the business model canvas can be replaced by various technological solutions of the digital economy [22]. The issue of expanding skills for the digital transformation of firms was addressed by M.J. Sousa and Á. Rocha. In their opinion, the processes of business model transformation as well as building employee skills are influenced by the modern economy such as the Internet of Things, artificial intelligence, augmented reality, nanotechnology, robotization, and digitalization; and the main digital learning sources were mobile, smartphone, and tablet applications-which are becoming popular among employees [23]. An important element for identifying the characteristics of the process of converting business models to digital solutions is the analysis of the quantitative and theoretical effects on digital transformation on entrepreneurial activity [24]. Another issue in the background of the theoretical and practical assumptions of the process of business model transformation towards the digital economy is building dynamic capabilities for digital reconfiguration, which was addressed by K.S.R. Warner and M. Wäger in their attempt to resolve the question of how firms in traditional economies create dynamic competences for established digital evolution and digital transformation as a process of building dynamic capabilities for continuing strategic renewal [25]. An important aspect is the analysis of the industry determinants of digital transformation in terms of their specificity, such as the luxury-branded hotel industry, where hotels need to go through digital transformation to meet the changing requirements of customers [26] and the aviation industry [27].

Research is also being conducted into the influence of digital transformation on the labor market. This is important from the perspective of the emergence of new structures and forms of employment of modern employees [28]. Digital transformation processes also concern the issue of digital transformation reporting between business and government [29]. It is important to apply digitalization to improve the 
quality of services, in particular initializing customer-oriented digital transformation in enterprises [30]. The issue of digitalization also applies to small and medium-sized enterprises which also observe the need to transform their business models to suit the digital economy [31]. Digitalization also changes the construction of value chains [32]. In addition, digital transformation allows for the creation of new technologies [22]. An interesting approach to digitalization, as well as a new space for it, can be provided by the concept of servitization. Servitization and Industry 4.0 are trends in the area of the digital reconfiguration of enterprises. Servitization serves to create additional value for the customer. Industry 4.0 is focused on creating value from the production process in terms of technology $[33,34]$. Enterprise Architecture should help designers of business models in the process of digital transformation [35]. The digital renovation of business models covers many areas of the organization's activities. The aim of the article is to investigate the reasons and the scope of the digitalization of business models of railway enterprises that hitherto belonged to the traditional sector. Noticeable technological progress in this sector contributes to the identification of the scientific gap which exists in terms of the explanation of the reasons, as well as the areas where digital transformation affects the structure of a value chain, and hence the transformation of existing traditional solutions in the sphere of business models into digital results.

The digital economy creates new opportunities to have a positive social impact. Extensive research into innovative companies confirms the key role of social aspects in shaping digital economy business models [36,37]. Technology platforms are conducive to building communities and allow for the achievement of tangible social effects. Actions to create social aspects may contribute to creating both financial [38] and non-financial value. The digital economy transforms the traditionally understood value chain into new forms of value creation [39]. The value migration process is significant in this respect $[40,41]$. An important feature of the modern economy is also value created in the life cycle of the business model [42] in the digital economy. Young companies can also see the positive features of social factors in their development process [43]. Social factors are important in ensuring the scalability of business models [44]. Social perspectives are also developed in hybrid enterprises [45]. Hybrid business models can be shaped based on social factors [46].

At the operational level, social interaction technologies (SIT) are particularly important for building social values [47]. In this way, social factors stimulate the activity of enterprises by building them in the configuration of business models. The relevant literature defines the proposals for identifying social factors in business models. One such proposal is the value drivers of social business models. These include shared values and integration news, responsible efficiency, supplementary impact [48]. They are important in the context of innovation design, especially in terms of the emerging concepts of modern economics [49]. Social factors are also considered in the conditions of the development of organizational knowledge in the area of converting business models from conventional business to social business orientation [50]. The relevant literature includes examples of the operationalization of business models based on social issues, e.g., with the use of the business model social canvas [51]. Social aspects play a key role in digital business models. Technology results in the emergence of new ways of communicating and building communities. The larger the community gathered around a given business model is, the greater its investment attractiveness and the ability to influence the ecosystem which it is embedded in. The gap that can be seen in the literature review process is the lack of research on the influence of the processes of the digital reconfiguration of company business models on creating social effects.

The impact of the digital evolution of the business models of railway enterprises on the creation of social perspectives was evaluated in the research process. This is crucial for the development of this sector as well as the need to create new business models supporting rail transport, affecting issues such as rail transport safety, its efficiency, and the reliability of transport processes. This article consists of the following areas: Section 1 presents the theoretical context of digital transformation and the context of the digitalization of contemporary business. Section 2 introduces the problem of digital transformation of business models in the railway sector-key areas of transformation. Section 2 
presents the social drivers of digitalization of business models of railway enterprises. In Section 3, the research methodology is described. Section 4 presents the results of research into the social aspects of digital evolution of the business models of railway enterprises. In Sections 5 and 6, discussions, conclusions and limitations are presented. In conclusion, future research which can be used for the development of the topic is signaled.

\section{Digital Reconfiguration of Business Models in the Railway Sector-Key Areas of Transformation and Social Drivers of the Digitalization of Business Models of Railway Enterprises}

Digital reconfiguration is a process experienced by many sectors of the economy and is now crucial to changes in the rail transport sector. The railway transport sector is traditional in terms of value chain construction. The main rail market entities include those in charge of maintenance, infrastructure managers, railway undertakings, certification bodies and bodies approving products and systems for operation, producers, and railway authorities. It is a complicated market from a legal perspective regarding the division of responsibilities of individual entities. The main problem faced by this sector in many countries is achieving competitiveness in relation to other branches of transport (road and air transport). In terms of legal conditions and the rules of competing in this sector, suitable business models of railway enterprises are established for them. Nowadays, the processes of reorganization in the railway sector and the opening of the railway market has changed meaningfully. Unbundling train operations and infrastructure railway transportation service provision is an important aspect in railway liberalization [52].

Based on a liberalization and harmonization approach in 1991 after 91/440 directives, unbundling was implemented in the railway sector. National railway reforms were implemented in European countries in accordance with railway packages [53]. The process of connecting the directives into a single piece of legislation began in 2010. The aim is to fulfil the requirements and assumptions of the Fourth Railway Package.

There are several management models of rail transport development in Europe. Two key approaches can be distinguished, namely the separated model and integrated model. The Separated Model means the complete separation of rail transport services and railway infrastructure management into separate legal entities that are not legally and financially linked (United Kingdom, Sweden). The essence of this approach is the full separation of the functions of infrastructure managers and railway undertakings (Poland). The Integrated Model means a vertically integrated structure. It has the nature of a holding company where the railway infrastructure is managed by a legal entity which also includes transport companies in its structure (Germany, Italy, and Austria) [54].

The approaches presented create suitable business ecosystems, where there is space for designing business models in the background of roles and tasks assigned to various railway market actors.

Sara Khayyam et al. [55] pay attention to extended business models in the railway sector as perceived by market players. Their proposed extended model combines the relationships between the Railway Operator, Infrastructure Manager, Electricity Market Operator, and Grid Owner and Energy Supplier. The business models of the railway sector can also be viewed in terms of their dynamics and key functions in connection with rail privatization, market liberalization, and centralization of management and integration. The impact of privatization and other structural changes on railways through business models is also considered. In this context, the following questions can be asked:

- How do organizational changes shape the functioning of railway enterprises?

- How to use knowledge to shape the forms and structures of railway enterprises?

- How to create value in railway enterprises? [56].

In terms of digital transformation, a business model is developing in the railways as a model of digital networks and artificial intelligence. The sources of innovative ideas in this area include market needs, the requirements of the production process, the development of existing external knowledge, as well as scientific and non-scientific knowledge based on experiences from the railway business [57]. 
In this way, many managers of railway enterprises search for the means by which to increase the efficiency of business models through digitalization. Technologies such as the Internet of Things, Mobile Technologies, Big Data, Cloud Technology, Artificial Intelligence, and Robotics influence the transformation from a traditional approach to business to a digitalized one [58]. The phenomenon of the improvement of new alternatives in information technology has made it possible to task existing value chains with innovative and often essential business models [59]. Digitalization requires delivering information and the representation of value creation processes in automated form [60]. With the help of digital business models and processes, internal company communication can be developed [61]. The use of digital solutions in the highly technologically saturated railway sector creates significant possibilities for their application in the organizational, management and technical spheres. The operationalization of digitalization processes in the field of railway solutions includes delivering on the following objectives:

- The digitalization of railways fosters better customer service and the availability of information on railway services.

- It provides high reliability and better communication.

- The use of Big Data on transport processes increases the attractiveness of the rail transport sector.

- The use of the Internet of Things and European Rail Traffic Management System (ERTMS) implementation will increase the capacity of the railway system [62].

Five main trends in the digitalization of rail transport have been identified. The use of the Internet of Things, cloud computing, the analytics of large data sets, as well as automation on railways allow for the implementation of solutions tailored to the concept of Railway 4.0, such as:

- the Connected Commuter,

- Mobility as a service (MaaS),

- Automatization and interoperability of traffic control systems (GoA4),

- Predictive Maintenance as a Service (PMaas),

- the Internet of Trains.

Digital transformation in the railway sector is not so much the application of new technologies in the operational activities of undertakings and infrastructure managers, as well as entities producing for the railway. Rather it is a radical change in existing business models and philosophy, allowing for the shaping of added value for many participants in the transport process and contributing to the realization of new mobility concepts [63]. In addition, digitalization covers the areas of activity of railway enterprises, such as preventive maintenance service, crowd-sourcing, co-development, electronic purchasing, data management systems, and others [64].

In shaping business models, digitalization means that not only are its social features observed, but they are also a key driver of the creation of value. In this respect, a new concept which is suitable for the business models of technology enterprises is servitization, a complex social phenomenon which dynamizes social factors in these companies [65]. Digital servitization concerns the use of digital tools for "the transformational processes whereby a company shifts from a product-centric to a service-centric business model and logic" [66]. The gradual shift from product-centered value propositions to complex product-service systems offerings, i.e., the servitization process, has led many production organizations to modify their business models and internal organization [67]. The conceptualization of servitization can be defined as a bottom-up and iterative process of business model contestation [68].

The platform approach and information modules are becoming the basis for new value propositions generated by manufacturers [69]. Generally, it is possible to define four unique servitizations which service network actors implement: customer co-creation, service extension, digitalization, and service benchmarking [70]. The factor responsible for shaping social relations within the concept of servitization is the creation of the servitization ecosystem, which ensures the management of diverse knowledge flows within the ecosystem [71]. The idea of servitization fits into the aspects of creating social relations 
in railway enterprises which undergo digital transformation. The technological nature of technical infrastructure management processes for ensuring the continuity of the functioning of the railway system, including cooperation between infrastructure managers and railway undertakings and other railway service operators, shape the technical and organizational ecosystem whose consistency can be achieved by digitizing processes that create a logical model of cooperation within the same business ecosystem. An appropriate tool for describing social relationships in the case of complex ecosystems is the use of a blockmodel role structure [72].

The implementation of digital solutions with the use of the servitization concept in the rail transport sector should help to improve the organization of individual business models, i.e., the entire railway ecosystem.

To sum up, attention can also be paid to possible disadvantages and problems related to digital transformation. In semantic terms, there are many terms that introduce a great deal of confusion in terms of the uniform interpretations of individual concepts. For example:

1. External Drivers of Digital Transformation-Digital Technology-Digital Competition-Digital Customer Behavior.

2. Phases of Digital Transformation- Digitization-Digitalization-Digital Transformation.

3. Strategic Imperatives of Digital Transformation-Digital Resources-Organizational Structure-Growth Strategy-Metrics and Goals [73].

In technological and legal terms, a significant problem on a global scale is, of course, the provision of the proper cybersecurity of technical systems on which the architecture of digitalization processes is embedded. The advantage of railway systems is that they are usually closed technical systems in a hybrid approach, i.e., cyber - physical systems, where the possibility of a cyber-attack is much more difficult. Cyber - physical systems emerged as a branch of embedded systems research specifically focused on the interaction between the computational elements and the physical entities [74]. Many safety-critical systems, such as those used for railway control, are unreachable from the Internet but have technical equipment located in geographically distributed shelters and used for actuation, power, and telecommunications [75]. Possible terrorist attacks in the railway sector with the possibility of using IT solutions are also a problem. Thus, it is crucial to link the principles of technical and functional safety to the methods of digital transformation. The safety and security goals are now the input by means of which to derive functional safety and security requirements. In this phase, the interference analyses first have to be undertaken in order to identify their impact on each other [76].

\section{Research Methodology}

As part of the scientific discussion, various research methods that may be applicable to the specificity of the research context which is the topic of discussion were verified by analyzing the specificity of the operation of the railway sector, including railway enterprises, in terms of the digital business models they use. The methods which may have the scientific potential to conduct proper scientific inference on a given research topic were taken into account. The analysis covered, inter alia, both the technological conditions of the railway sector and relevant research methodologies, as well as organizational and management conditions and the related research methodologies. The conducted synthesis indicated that the methods used in social sciences will be optimal solutions. Although the methods of discrete simulation are applicable to the analysis of transport systems, including the safety criterion, they were not applicable to the research. For example, the method of discrete research is aimed at obtaining information that will allow for the assessment of the correctness of the decision taken in any situation, at any time, while at the same time assessing the ex post and ex ante impacts. However, this method does not apply to the research questions and hypotheses posed. Therefore, an analysis of the linear relationship between the variables which determine the impact of social aspects on the determinants of digital business models was applied. The scientific goal of the research questions and hypotheses was to determine the statistical relationships between individual variables. In this 
approach, the dependent (response) variable in the research model is the digital business model, while the independent (explanatory) variables are social perspectives described in the research hypotheses and referring to conditions specific to the rail transport sector.

The goal of the research is to assess the impact of the digital conversion of the business models of railway enterprises on the creation of social effects.

The research procedure covered [77]:

1. Identifying a research topic and defining a research problem.

2. Determining how to conduct research.

3. Analyzing the literature on the subject of the railway transport sector, social perspectives of the digital economy, and the digital conversion of business models.

4. Analyzing the development of the concept and defining the key components of a digital business model and the development of its main trends, taking strategic thinking into account.

5. Identifying factors affecting the digital transformation of the business models of railway enterprises.

6. Conducting quantitative research on a selected sample of railway enterprises in relation to their digital transformation.

7. Collecting and analyzing data using statistical methods.

8. Verifying research hypotheses and inferring conclusions based on research results.

9. Writing a report.

\subsection{Research Hypotheses}

Five research hypotheses were formulated with reference to the research problem:

Hypothesis 1 (H1). The digital transformation of the business models of railway enterprises enables the socialization of their business models.

Hypothesis 2 (H2). The business models of railway enterprises increase the level of mutual integration through digital transformation.

Hypothesis 3 (H3). Servitization affects the socialization of the business models of railway enterprises.

Hypothesis 4 (H4). Process integration of railway enterprises increases the level of business model socialization.

Hypothesis $\mathbf{5}$ (H5). The digitalization of the business models of railway enterprises increases the opportunities for the development of social factors.

The research model is presented in Figure 1.

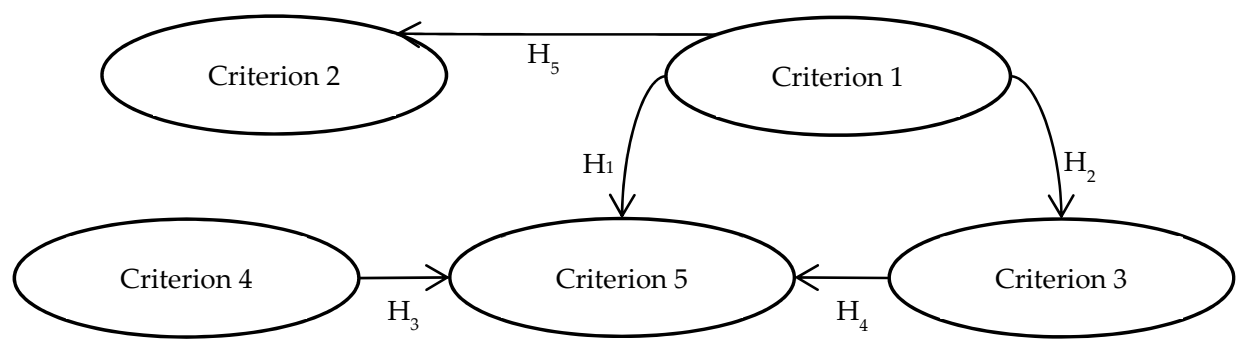

Figure 1. Research model.

\subsection{Research Sample}

The research covered railway undertakings and infrastructure managers-all firms operating on the Polish market, amounting to 120 railway operators in total. The criteria for selecting enterprises, as well as their characteristics, were as follows: the range of activity, company size, and form of ownership. 
Most of the railway enterprises surveyed were enterprises with over 250 employees, which accounted for $48 \%$ of the sample. They were followed by $26 \%$ medium-sized enterprises (with 50-249 employees) and $26 \%$ small enterprises (10-49 employees) (Figure 2a). There was no microenterprise on the list. Among the organizations surveyed, private enterprises were predominant ( $63 \%$ of the sample). The remainder were public enterprises (Figure $2 \mathrm{~b}$ ). $68 \%$ of enterprises operated domestically, and $32 \%$ were international enterprises (Figure 2c).

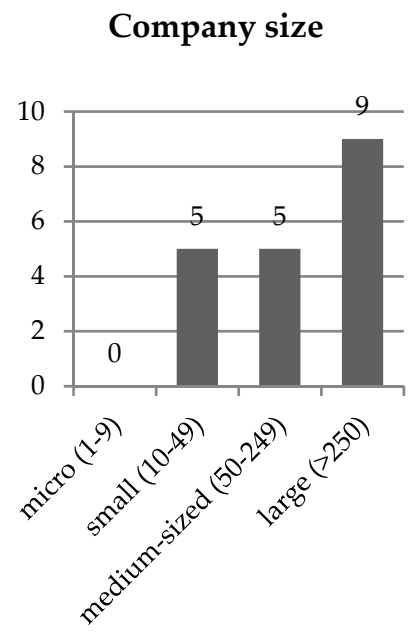

(a)

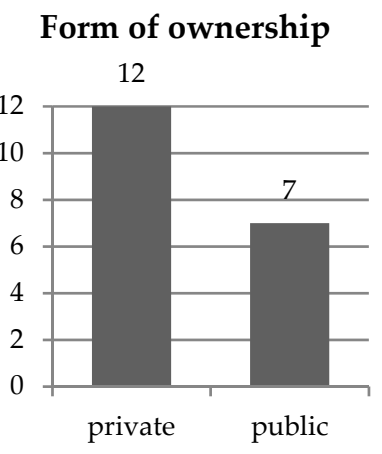

(b)

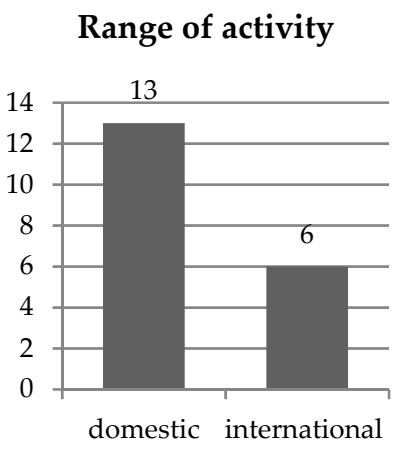

(c)

Figure 2. Basic data on the railway enterprises investigated.

The article uses the method of selecting a research sample in the form of purposive sampling. Such units were selected for the sample so that they most accurately reflect the size and structure of the characteristics of the general population, i.e., railway market enterprises. This allows for valuable results that are difficult to obtain with random sampling. The essence of purposive sampling, and therefore non-random sampling, is the formulation of an unambiguous rule for creating a research sample, allowing for the selection of objects with predetermined characteristics. In such a situation, the selection of research units for the sample is not determined by chance (fate), but by a specific goal and set of object characteristics. Therefore, the use of purposive sampling of railway enterprises in the research is justified.

As part of the study of the digital transformation of the business models of railway enterprises, five key criteria were identified. The specific issues addressed within the five key research areas covered the following issues:

1. Digital transformation of the business models of railway enterprises.

2. Possibilities of the development of social factors through digital transformation.

3. Mutual process integration of railway enterprises through digital transformation.

4. Servitization of railway enterprises.

5. Socialization of the business models of railway enterprises.

After the questionnaires were compiled, taking into account the above-defined criteria and sub-criteria, they were sent to railway undertakings and infrastructure managers, who were asked to evaluate the criteria in relation to the functioning of their company and to complete them according the following scale (Table 1). 
Table 1. The scale used to evaluate the company in terms of sub-criteria.

\begin{tabular}{cccccc}
\hline Scale & $\mathbf{1}$ & $\mathbf{2}$ & 3 & $\mathbf{4}$ & $\mathbf{5}$ \\
\hline Phrase & I strongly disagree & I somewhat disagree & $\begin{array}{c}\text { I neither agree } \\
\text { nor disagree }\end{array}$ & I somewhat agree & I strongly agree \\
\hline
\end{tabular}

Based on the designed research model, statistical relationships were calculated, namely, the correlation between the overall ratings obtained from firms within the criteria. The strength of correlation relationships is defined as $0.9-1.0$ - the relationship is practically complete, below 0.2 -weak correlation (practically no relationship).

\section{The Effects of Research into the Social Perspectives of the Digital Evolution of the Business Models of Railway Enterprises}

In order to investigate the extent to which data obtained on the basis of questions are compared across pairs of hypotheses, these relations were also presented in the form of scatter charts along with the trend functions adapted to them. The polynomial trend line was chosen as it is the closest fit to the data. A polynomial trend line is used if data values are both rising and falling. Trend lines, also known as lines of best fit or regression lines, graphically represent trends in data series and are commonly used when creating forecast charts. The number of data fluctuations can determine the degree of the polynomial. A second-order polynomial trend line has one maximum or minimum, while a third-order polynomial trend line has up to two maximums or minimums, and a fourth-order polynomial has up to three maximums or minimums. By selecting the option to display the equation and R-squared, we obtain the form of a regression equation and the R-squared statistic for a quick assessment. There is a non-linear relationship between the dependent variable and independent variable. The individual forms of the trend were selected based on the assessment of the point scattering corresponding to the results for the hypotheses presented in the Cartesian system. Thus, five graphs presenting relationships within the framework of the hypotheses were constructed (Figure 3). According to the hypotheses, the correlations between the pairs of variables were analyzed. The trend functions closest to the given points were assigned to them.

Standard errors of the structural parameters were calculated for each function and presented in the table below together with their standard errors. The issue of whether the model explains the shaping of the dependent variable to a sufficiently high degree was also checked. This was done by means of measures of the model's compliance with empirical data, i.e., the coefficient of random variation, coefficient of convergence and the coefficient of determination (Table 2).

Table 2. Trend functions for hypotheses and values of the coefficients of random variation, convergence, and determination.

\begin{tabular}{|c|c|c|c|c|}
\hline Hypothesis & Trend Function & $\begin{array}{c}\text { Coefficient of } \\
\text { Random Variation } W_{e}\end{array}$ & $\begin{array}{c}\text { Coefficient of } \\
\text { Convergence } \varphi^{2}\end{array}$ & $\begin{array}{c}\text { Coefficient of } \\
\text { Determination } R^{2}\end{array}$ \\
\hline 1 & $\begin{array}{l}\hat{X} 5=-41.81+39.54 X 1-11.05 X 1^{2}+1.01 X 1^{3} \\
(10.37) \quad(9.60) \quad(2.86) \quad(0.28)\end{array}$ & $14 \%$ & 0.31 & 0.69 \\
\hline 2 & $\begin{array}{l}\hat{X} 3=-8.44+9.93 \times 1-2.60 X 1^{2}+0.22 X 1^{3} \\
(9.83) \quad(9.10) \quad(2.71) \quad(0.26)\end{array}$ & $14 \%$ & 0.75 & 0.25 \\
\hline 3 & $\begin{array}{l}\hat{X} 5=-3.34+3.28 X 4-0.34 X 4^{2} \\
(5.24) \quad(2.98) \quad(0.41)\end{array}$ & $19 \%$ & 0.59 & 0.41 \\
\hline 4 & $\begin{array}{l}\hat{X} 5=-22.58+13.64 X 3-1.70 X 3^{2} \\
(7.59) \quad(4.03) \quad(0.53)\end{array}$ & $17 \%$ & 0.50 & 0.50 \\
\hline 5 & $\begin{array}{l}\hat{X} 2=-5.15+6.72 X 1-1.69 X 1^{2}+0.15 X 1^{3} \\
(7.40) \quad(6.85) \quad(2.04) \quad(0.20)\end{array}$ & $11 \%$ & 0.53 & 0.47 \\
\hline
\end{tabular}




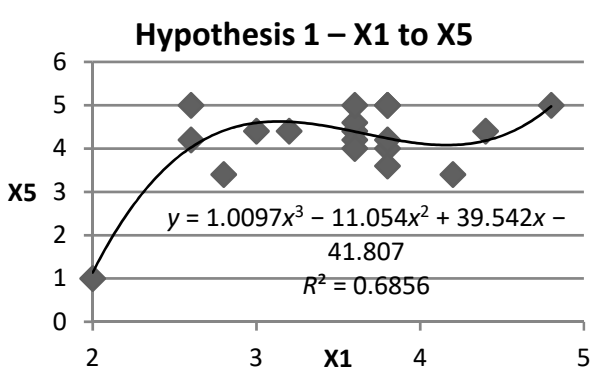

(a)

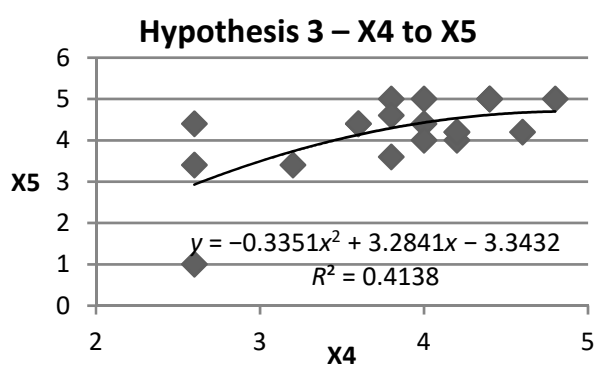

(c)

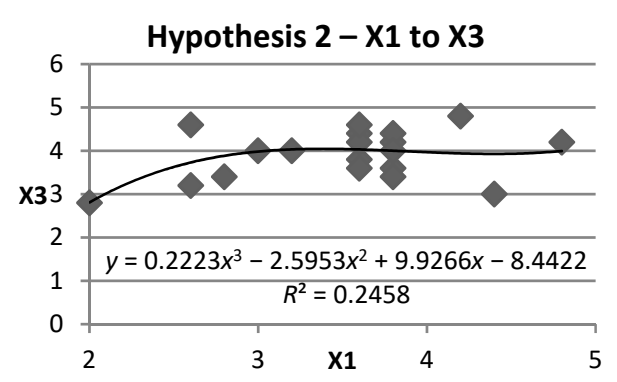

(b)

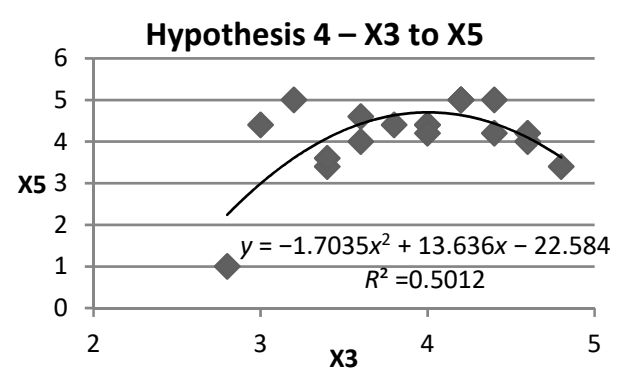

(d)

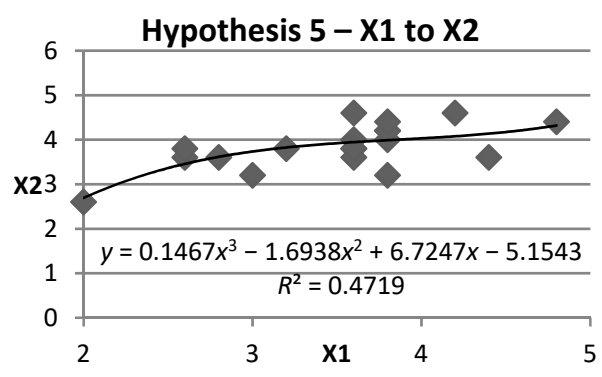

(e)

Figure 3. Relationships between variables within the framework of the hypotheses: (a) Hypothesis 1-X1 to X5; (b) Hypothesis 2-X1 to X3; (c) Hypothesis 3-X4 to X5; (d) Hypothesis 4-X3 to X5; (e) Hypothesis $5-\mathrm{X} 1$ to $\mathrm{X} 2$.

The following formula was used to calculate the coefficient of random variation:

$$
W_{e}=\frac{S_{e}}{\bar{Y}} \cdot 100 \%,
$$

This coefficient shows what part of the arithmetic mean of the dependent variable of the models constitutes the standard deviation of the rest. The lower the value of this coefficient, the better the fit. The lowest value was shown for Hypothesis 5-The digitalization of the business models of railway enterprises increases the opportunities for the development of social factors, amounting to $11 \%$, which means that it was good to adjust the models to the empirical data. The coefficient of random variation $W_{e}$ had the highest value in the case of Hypothesis 3, in which the issue of whether servitization affects the socialization of the business models of railway organizations was examined-it amounted to $19 \%$. If the critical value of the coefficient of random variation $W^{*}$ at the level of $15 \%$ was assumed in advance, it means that in three cases $W_{e} \leq W^{*}$, which means that the model is considered to be sufficiently fitted to the empirical data. For hypotheses 3 and 4 , the fit is considered too weak because the value of $W_{e}$ is $19 \%$ and $17 \%$, respectively. 
The coefficient of convergence is expressed by the formula:

$$
\varphi^{2}=\frac{\sum_{t=1}^{n} e_{t}^{2}}{\sum_{t=1}^{n}\left(Y_{t}-\bar{Y}\right)^{2}},
$$

and indicates what portion of the total variation of the dependent variable is not explained by the model. It has values in the range [0;1]. In the case of the coefficient of convergence $\varphi^{2}$ there was huge variation, because the highest value occurred in the case of Hypothesis 2 (The business models of railway enterprises increase the level of mutual integration through digital transformation) -0.75 , and the lowest for Hypothesis 1 (The digital transformation of the business models of railway enterprises enables the socialization of their business models) -0.31 . The better the fit of the model to the data, the closer the coefficient $\varphi^{2}$ is to zero. The fit of the models presented varies from high $\left(\varphi^{2}=0.31\right)$ to low $\left(\varphi^{2}=0.75\right)$.

The $R^{2}$ coefficient of determination was calculated, which says what part of the total variation of the dependent variable is determined by independent variables. It is expressed as

$$
R^{2}=\frac{\sum_{t=1}^{n}\left(\hat{Y}_{t}-\bar{Y}\right)^{2}}{\sum_{t=1}^{n}\left(Y_{t}-\bar{Y}\right)^{2}}
$$

The coefficient of determination $R^{2}$ was calculated as the squared values of correlations. In order to determine a better fit within the hypotheses, the trend functions were exponential functions to the power of three. For each of the trend functions, standard errors of their structural parameter were calculated. The coefficient of random variation, coefficient of convergence, and coefficient of determination were calculated in order to check whether the model explains the development of the dependent variable to a sufficiently high degree. The better the fit, is the closer to one the coefficient. The best fit occurred for the function for Hypothesis 1 (The digital transformation of the business models of railway enterprises enables the socialization of their business models), where the value of the coefficient of determination was $R^{2}=0.69$. The least-fitting function was the trend function for Hypothesis 2 (The business models of railway enterprises increase the level of mutual integration through digital transformation), where $R^{2}=0.25$. Negative correlation does not occur.

The following relationship takes place between the coefficient of convergence and the coefficient of determination:

$$
\varphi^{2}+R^{2}=1,
$$

By contrast, the square root of $R^{2}$ coefficient of determination is the coefficient of multiple correlation. The decision was made to check the hypothesis pertaining to the significance of the coefficient of multiple correlation in order to check whether the fit between the model and the empirical data was sufficiently large. This statistic has a $F$ Fisher-Snedecor distribution of $m_{1}=k$ and $m_{2}=n-k-1$ degrees of freedom. This was verified using statistics:

$$
F=\frac{R^{2}}{1-R^{2}} \cdot \frac{n-k-1}{k},
$$

The critical value $F^{*}$ was read from the $\mathrm{F}$ test tables at the given significance level $\gamma=0.05$ and degrees of freedom $m_{1}$ and $m_{2}$ (Table 3). 
Table 3. Values of $F$ statistics for the hypotheses.

\begin{tabular}{|c|c|c|c|c|}
\hline Hypothesis & $\begin{array}{c}\text { Coefficient of } \\
\text { Determination } R^{2}\end{array}$ & $\begin{array}{c}\text { Values of } F \\
\text { Statistics }\end{array}$ & Critical Value $F^{*}$ & Conclusion \\
\hline 2 & 0.25 & 1.63 & 3.29 & $\begin{array}{l}F<F^{*} \text {, the coefficient of multiple } \\
\text { correlation is insignificantly } \\
\text { different from zero, and the fit of } \\
\text { the model to the data is too weak. }\end{array}$ \\
\hline 1 & 0.69 & 10.91 & 3.29 & \multirow{4}{*}{$\begin{array}{l}F>F^{*} \text {, the coefficient of multiple } \\
\text { correlation is significant and the } \\
\text { fit of the model to the data is } \\
\text { sufficiently high. }\end{array}$} \\
\hline 3 & 0.41 & 5.65 & 3.63 & \\
\hline 4 & 0.50 & 8.04 & 3.63 & \\
\hline 5 & 0.47 & 4.47 & 3.29 & \\
\hline
\end{tabular}

The value of $F$ statistics in most cases was $F>F^{*}$, which means that multiple correlation coefficients were significant, and the degree of fit of the model to the data was sufficiently high. For hypothesis 2 , the coefficient of multiple correlation was insignificantly different from zero $\left(F<F^{*}\right)$. The fit of the model to the data was too small.

The meaning of the structural parameters $\alpha 1, \alpha 2, \alpha 3$ of econometric models was calculated to check whether the independent variables significantly affect the dependent variables. It used the formula:

$$
I_{i}=\frac{\left|a_{i}\right|}{S\left(a_{i}\right)}
$$

where $a_{i}$ is the value of the structural parameter evaluation, and $S\left(a_{i}\right)$-the standard error of the structural parameter estimation. From the $t$-Student's test tables, the critical value $I^{*}$ was read with the assumed significance level $\gamma=0.10$ and for $n-k-1$ degrees of freedom. The empirical values of $t$-Student's statistics corresponding to individual structural parameters were calculated (Table 4).

Table 4. Values of $t$-Student's statistics for the hypotheses.

\begin{tabular}{|c|c|c|c|}
\hline Hypothesis & $\begin{array}{l}\text { Value of } I_{i} \\
\text { Statistics }\end{array}$ & Critical Value $I^{*}$ & Conclusion \\
\hline 1 & $\begin{array}{l}I_{1}=4.119 \\
I_{2}=3.860 \\
I_{3}=3.650\end{array}$ & 1.753 & $\begin{array}{l}\text { The } a_{i} \text { parameter differs significantly from zero and } \\
\text { the independent variable X1 has a significant influence } \\
\text { on the dependent variable X5. }\end{array}$ \\
\hline 2 & $\begin{array}{l}I_{1}=1.091 \\
I_{2}=0.956 \\
I_{3}=0.848\end{array}$ & 1.753 & $\begin{array}{l}\text { The } a_{i} \text { structural parameter differs insignificantly from } \\
\text { zero, and the independent variable X1 does not } \\
\text { significantly influence the dependent variable X3. }\end{array}$ \\
\hline 3 & $\begin{array}{l}I_{1}=1.102 \\
I_{2}=0.809\end{array}$ & 1.746 & $\begin{array}{l}\text { The } a_{i} \text { structural parameter differs insignificantly from } \\
\text { zero, and the independent variable X4 does not } \\
\text { significantly influence the dependent variable X5. }\end{array}$ \\
\hline 4 & $\begin{array}{l}I_{1}=3.385 \\
I_{2}=3.235\end{array}$ & 1.746 & $\begin{array}{l}\text { The } a_{i} \text { parameter differs significantly from zero and } \\
\text { the independent variable X3 has a significant influence } \\
\text { on the dependent variable X5. }\end{array}$ \\
\hline 5 & $\begin{array}{l}I_{1}=0.982 \\
I_{2}=0.829 \\
I_{3}=0.743\end{array}$ & 1.753 & $\begin{array}{l}\text { The } a_{i} \text { structural parameter differs insignificantly from } \\
\text { zero, and the independent variable X1 does not } \\
\text { significantly influence the dependent variable X2 }\end{array}$ \\
\hline
\end{tabular}

In only two cases the $a_{i}$ structural parameters differ significantly from zero and the independent variable significantly affects the dependent variable:

- Hypothesis 1: The digital transformation of the business models of railway enterprises enables the socialization of their business models 
- Hypothesis 4: Process integration of railway enterprises increases the level of business model socialization.

Considering that, out of 10 infrastructure managers and 110 railway enterprises, 19 responses to the questionnaires sent were received, the decision was made to determine the necessary number of independent measurements for the sample, which should be conducted so that with a confidence interval of 0.95 , the estimated rating of " 5 . The socialization of the business models of railway enterprises" was with a maximum error of 0.45 points, if the preliminary sample of 19 responses gave results similar to those of X5. This was calculated using the following formula:

$$
n=\frac{t_{\gamma}^{2} s^{2}}{d^{2}}
$$

The variance for data was $s^{2}=0.8137$, the standard error was $d=0.45$, the significance level was set at $\gamma=0.05$, and 19 tests were conducted, so $m=18$. From the $t$-Student distribution, the parameter $t_{\gamma}=2.101$.

$$
n=17.74 \approx 18,
$$

This means that a suitable number of completed survey questionnaires were received. The studied sample is representative (for the population of infrastructure managers and railway undertakings-10 infrastructure managers and 110 railway undertakings), which allows for the generalization of the conclusions from the study of this sample to the entire population. Based on the statistical inference from the sample considered representative, the research results can be generalized. The adopted representativeness assumes that, apart from the variables on the basis of which the researcher selected the respondents for the research, there are no other significant variables that could affect the results obtained in the sample. It gives results similar to those which we could expect of the entire population if it were tested, which allows for the generalization of conclusions from the research sample to the entire population. In other words, it is a miniature of the surveyed population that reflects its most important features, because the size of the entire railway sector in Poland is known to amount to 120 enterprises.

The confidence intervals for the mean of the data obtained were calculated, which allowed for the estimation of the probable interval where the mean is located, with the assumption that the variance of the population is unknown. The following interval was used to estimate the confidence interval, because it was assumed that $n<30$ :

$$
\left(\bar{X}-t_{\alpha, n-1} \sqrt{\frac{s^{2}}{n}}, \bar{X}+t_{\alpha, n-1} \sqrt{\frac{s^{2}}{n}}\right),
$$

where

$\bar{X}$-the mean of the sample,

$t_{\alpha, n-1}$-distribution function of $t$-Student's distribution for the significance level $\alpha$ and $\mathrm{n}-1$ degrees of freedom,

$s^{2}=\frac{1}{n-1} \sum_{i=1}^{n}\left(X_{i}-\bar{X}\right)^{2}$-variance calculated from the sample,

$n$-sample size.

The following confidence intervals were received (Table 5).

Table 5. Confidence interval for the mean.

\begin{tabular}{cccccc}
\hline Variables & $\mathbf{X 1}$ & $\mathbf{X} 2$ & $\mathbf{X 3}$ & $\mathbf{X} 4$ & $\mathbf{X 5}$ \\
\hline $\begin{array}{c}\text { Confidence interval } \\
\text { for the mean }\end{array}$ & $(3.18 ; 3.83)$ & $(3.60 ; 4.09)$ & $(3.63 ; 4.18)$ & $(3.49 ; 4.13)$ & $(3.72 ; 4.62)$ \\
\hline
\end{tabular}


The middle values for this ranges indicate that the highest value is expected for the answer to criterion 5 (Socialization of the business models of railway enterprises) from the range $(3.72 ; 4.62)$. The lowest-rated issues were in criterion 1 (Digital transformation of the business models of railway enterprises) in the range $(3.18 ; 3.83)$.

The consistency of the scale was verified thanks to Cronbach's Alpha, which takes values ranging from [0; 1]. A reading of $\alpha>0.7$ is testament to the high reliability of the scale. This coefficient indicates to what extent a set of variables is consistent. If all positions were perfectly reliable and measured the same thing, the coefficient $\alpha=1$. Cronbach's Alpha was estimated from the following formula:

$$
\alpha=\frac{K}{K-1}\left(1-\frac{\sum_{i=1}^{K} \sigma_{\text {question }}^{2}}{\sigma_{\text {set }}^{2}}\right),
$$

where

$K$-number of questions,

$\sigma_{\text {question }}^{2}$-variance for the responses that were obtained for a question $i$,

$\sigma_{\text {set }}^{2}$-variance from the sum of responses to all the questions for individual firms,

Question $_{i}$ - responses obtained for individual questions by all the firms.

The value of Cronbach's Alpha was 0.90. The greater the reliability of the scale, the higher the value of the coefficient $\alpha$. As such, the reliability of this study is very high.

The values of correlation between individual criteria obtained in the context of the research hypotheses as part of the adopted research model are presented in Figure 4.

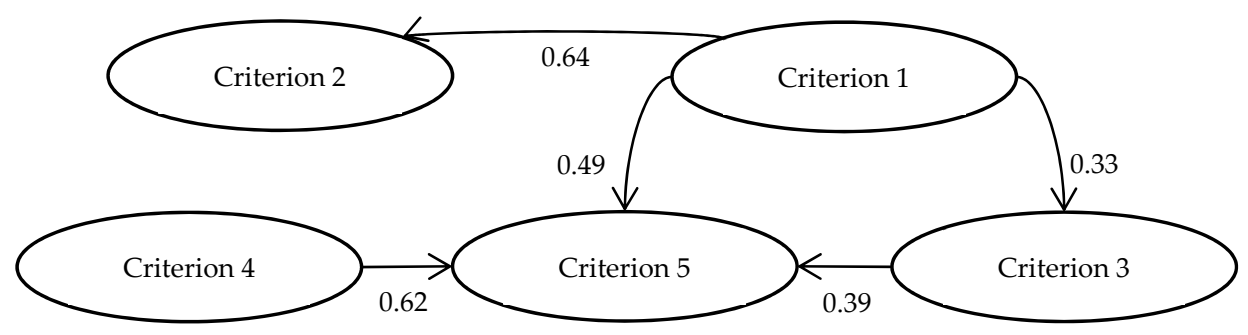

Figure 4. Graphical presentation of hypotheses together with values of correlation between the examined variables.

The highest level of correlation was achieved between the digitalization of the business models of railway enterprises and the possibilities of the development of social factors (0.64) and for the relationship between the servitization of railway enterprises and the socialization of the business models of railway enterprises (0.62). This means that social factors play a key role in the process of the digital transformation of the business models of railway enterprises. A low level of correlation was achieved in the relationship between the digital transformation of the business models of railway enterprises and the mutual process integration of railway enterprises through digital transformation. This result does not prove the importance of digitalization, namely its impact on improving the operational activity of companies. This result is astonishing, especially in the context of railway enterprises operating on one platform constituting a technical ecosystem, i, a track system where mutual dependencies in the relationships between infrastructure managers and railway undertakings and between companies should be based on digital solutions. This result is probably due to the still insufficient level of technological progress of railway operators on the Polish market. Similarly, a weak level of correlation occurs between the mutual process integration of railway enterprises through digital transformation and the socialization of the business models of railway enterprises. It seems right to say that in the future, as the level of digitalization and implementation of modern technologies increases, the level of correlation between these variables should increase as well. 


\section{Discussion}

The model of scientific research presented in the article was used to assess the impact of social factors on the digital reconfiguration of the business models of railway enterprises. Social factors are an important result of the digital transformation of enterprises operating in the railway sector. The research goals are in line with the modern trend of building the digital identities of high-tech sectors of the economy, including rail transport. Business models play a key role in railway enterprises. This is especially important at a time when the digital transformation related to both the organizational and technological aspects of operating railway enterprises, especially railway undertakings and infrastructure managers, is gaining importance. Digitalization in these enterprises is related to the technical systems they use and their architecture. Such an approach shapes the image of a railway enterprise as a high reliability organization with a high level of effectiveness. Digitalization facilitates the development of these enterprises, generating social impact, the recipients of which are various stakeholders of railway enterprises. For such assumptions, research hypotheses were developed and positively verified. The level of correlation between the defined variables ranges from moderate $(\mathrm{H} 1$, $\mathrm{H} 2, \mathrm{H} 4$ hypotheses) to high correlations (H3, $\mathrm{H} 5$ hypotheses).

The observation and analysis of business models in the rail transport sector is currently under pressure to adapt technology to standardize interfaces between different devices. This is the purpose of the digitalization of technology and business models. Factors relevant to digitalization are noticeable in the context of technological, organizational, and operational development. The aspects of the digital economy will therefore be the determinant of the design and implementation of digital business models in this sector.

A departure from analog solutions in favor of the digital economy, along with ensuring the standardization of the interface between devices, can be observed. This is vitally important in the technology-organization role of the human factor relationship. The issue of safety plays a leading role in this context. The article refers to the aspect of cybersecurity in terms of system security measures aimed at ensuring the proper operation of technical systems, primarily in the context of the ability of railway enterprises to provide railway services (railway undertakings) and to manage railway traffic along with railway infrastructure (infrastructure managers). It should be noted that the basic parameter which describes the specificity of the railway sector, and thus its business models, is railway traffic safety, which is a social expectation resulting directly from the feeling of a state of no hazards. It is therefore of a social nature and must be embedded in the digital business models of railway enterprises. The key issue is cybersecurity, which is a priority in many companies in the era of the digitalization of the economy. The implemented digital solutions improve railway traffic safety. Ensuring the expected level of safety in rail transport is a key determinant of the business models of these enterprises. Railway traffic safety increases the chances of increasing trust and improving relationships with stakeholders. The improvement of the quality of machine-machine, human-machine and human-human interfaces is essential for social impact. Moreover, digital solutions are used to create positive relationships with suppliers/partners. Social capital is built by railway market participants. Digital solutions support the use of social effects (economy, ecology, and ethics) and improve the effectiveness of processes. It should also be noted that digital solutions contribute to improving the ability to cooperate within the organizational and technical solutions of the railway ecosystem. Railway enterprises build cooperation platforms using digital technologies. Research shows that railway enterprises use digital solutions that perfectly match the solutions of other companies in this sector. They use solutions based on the shift from a product/service-oriented model to a service-oriented business model.

The organizations analyzed in this study are adapting their business models in a bottom-up and iterative manner. They create business models which co-create value with customers. This is important when it comes to identifying quality attributes relevant to the processes of transportation of goods and people. An important element of the business models of railway enterprises is trust between business partners, built by designing a network of values involving all actors in the railway market (including positive social impact). 


\section{Conclusions}

Based on the conducted research related to the attempt to evaluate the relationship between social factors and the processes of digital transformation of the business models of railway enterprises, a series of conclusions were reached in order to identify the assumptions of the theory in this respect.

1. The digital transformation of the business models of railway enterprises increases the opportunities for the development of social factors.

2. The business models of railway enterprises increase the level of mutual integration through digital transformation.

3. Servitization affects the socialization of the business models of railway enterprises.

4. The process integration of railway enterprises contributes to an increased level of business model socialization.

5. The effective digital transformation of the business models of railway enterprises is possible. Social factors play a crucial role in this development.

Solutions that are used by railway enterprises and have an impact on the configuration and operationalization of their business models include the concept of the Connected Commuter, a Predictive Maintenance as a Service (PMaas), Mobility as a service (MaasS), the automatization and interoperability of traffic control systems, the concept of the Internet of Trains, railway traffic automation, and the concept of cloud computing.

The conditions of the railway sector determine the approach to the digitalization of the business models of these firms. Technological perspectives and relational determinants related to the strong mutual cooperation required between railway enterprises and infrastructure managers have particular significance in this context. In this approach, the digitalization of processes is important. The approach also significantly reveals the development of the socialization of business models, which is conceptualized and operationalized through the development of social factors based on digital transformation. In recapping the research results, the next directions of research in this area have been indicated. They may contain:

- The determinants of the servitization process and its impact on the improvement of digital features of the business models of railway enterprises.

- Further exploration of social aspects of the digital transformation process of business models, especially in terms of the complementarity of processes implemented by infrastructure managers and railway undertakings.

- The development of specialized technologies and solutions suitable for railway transport and their impact on managing the processes of the digitalization of the business models of these organizations.

The proposals presented do not fully cover the complexity of the study of the processes in question. Further requirements in this area may be revealed in the course of further research.

To summarize the research results, possible other research in a similar scope should be referred to. It can be concluded that such an approach to the social perspective in the context of the digital business models of railway enterprises has been poorly explored so far. There is not a great deal of research into the development of digital business models, in particular considered in terms of social criteria. Hence, this topic seems to be very important and necessary for appropriate scientific inference.

Limitations which should be first indicated include the conditions of the railway sector, the specificity of which determines the approach of the sector to the course of digitalization of the business model, which is based on the strong impact of technological factors. Because the railway system is closed, the cooperation platform between infrastructure managers and railway undertakings strongly depends on legal features, which significantly affects the shape of the business models they use. The survey questionnaires were filled in by the representatives of the key management personnel of 
the enterprises surveyed, which should not be a limitation when it comes to drawing conclusions. The early phase of digital technology development in Poland can also be a limiting factor in drawing conclusions. Therefore, it would seem reasonable to repeat this study in the near future.

Thus, it is possible to define specific restrictions for certain enterprises in the railway sector and restrictions for enterprises in other sectors in general. Currently, the railway sector functions in the form of a hybrid approach. This means that digital factors are increasingly developing, but in many areas, activities are conducted in analog terms. This is a significant limitation. In addition, the social aspect plays an increasingly important role in the railway sector, but different countries have different experiences in this respect in technological, organizational, and social terms. In terms of general limitations, it should be noted that each sector determines individual features and attributes. In view of the above, it is worth interpreting it in a dimension relevant to the sectoral conditions of other areas of science and practice.

Summing up the scientific discussion, reference should be made to the contribution of the article and the obtained results to scientific knowledge in the field of management and quality sciences. The authors believe that this topic is of particular importance for the development of the railway sector, both from the social perspective and from the perspective of digital transformation. This approach allows for the combination of technological, managerial and social needs into one comprehensive approach that allows enterprises from the entire railway sector to open up to many cognitive spaces. What is important is that shaping the digital business models of the railway enterprises requires a new perspective, the result of which is social aspects both in the dimension of sectoral conditions suitable for a high reliability organization with a high level of effectiveness, and the values themselves in the social dimension. This can be a strong platform for further scientific exploration in this important scientific area.

Author Contributions: Conceptualization, M.J.; Formal analysis, A.J. and M.J.; Investigation, A.J.; Methodology, M.J.; Resources, A.J.; Supervision, A.J. All authors have read and agreed to the published version of the manuscript.

Funding: This research received no external funding.

Conflicts of Interest: The authors declare no conflict of interest.

\section{References}

1. Wirtz:, B.W. Digital Business Models, Concepts, Models, and the Alphabet Case Study; Springer: Cham, Switzerland, 2019. [CrossRef]

2. Reis, J.; Amorim, M.; Melão, N.; Matos, P. Digital Transformation: A Literature Review and Guidelines for Future Research. In Trends and Advances in Information Systems and Technologies; Rocha, Á., Adeli, H., Reis, L.P., Costanzo, S., Eds.; WorldCIST'18. Advances in Intelligent Systems and Computing; Springer: Cham, Switzerland, 2018; Volume 745. [CrossRef]

3. Zaoui, F.; Souissi, N. Roadmap for digital transformation: A literature review. Procedia Comput. Sci. 2020, 175, 621-628. [CrossRef]

4. Singh, A.; Hess, T. How chief digital officers promote the digital transformation of their companies. MIS Q. Exec. 2017, 16, 1-17. [CrossRef]

5. Fischer, M.; Imgrund, F.; Janiesch, C.; Winkelmann, A. Strategy archetypes for digital transformation: Defining meta objectives using business process management. Inf. Manag. 2020, 57, 103262. [CrossRef]

6. Negroponte, N. Being Digital. Vintage Books; Hodder \& Stoughton: New York, NY, USA, 1995.

7. Fors, A.C. The Ontology of the Subject in Digitalization. In Handbook of Research on Technoself: Identity in a Technological Society; IGI Global: Hershey, PA, USA, 2013; pp. 45-63. [CrossRef]

8. Yoo, Y. Computing in everyday life: A call for research on experiential computing. MIS Q. 2010, 34, 213-231. [CrossRef]

9. Hess, T.; Matt, C.; Benlian, A.; Wiesböck, F. Options for formulating a digital transformation strategy. MIS Q. Exec. 2016, 15, 123-139.

10. Rachinger, M.; Rauter, R.; Müller, C.; Vorraber, W.; Schirgi, E. Digitalization and its influence on business model innovation. J. Manuf. Technol. Manag. 2018, 30, 1143-1160. [CrossRef] 
11. Vial, G. Understanding digital transformation: A review and a research agenda. J. Strateg. Inf. Syst. 2019, 28, 118-144. [CrossRef]

12. Bauernhansl, T. Cognitive Production Systems-Technologies and Business Impacts. In Proceedings of the NEXCON: First International Virtual Congress on Smart Manufacturing, Stuttgart, Germany, 28 February 2019.

13. Barbu, C.M.; Bratu, R.Ş.; Sirbu, E.M. Business Models of the Sharing Economy. Rev. Int. Comp. Manag. 2018, 19, 154-166. [CrossRef]

14. Borges, A.F.S.; Laurindo, F.J.B.; Spínola, M.M.; Gonçalves, R.F.; Mattos, C.A. The strategic use of artificial intelligence in the digital era: Systematic literature review and future research directions. Int. J. Inf. Manag. 2020, 102225. [CrossRef]

15. Metallo, C.; Agrifoglio, R.; Schiavone, F.; Mueller, J. Understanding business model in the Internet of Things industry. Technol. Forecast. Soc. Chang. 2018, 136, 298-306. [CrossRef]

16. Loebbecke, C.; Picot, A. Reflections on societal and business model transformation arising from digitization and big data analytics: A research agenda. J. Strateg. Inf. Syst. 2015, 24, 149-157. [CrossRef]

17. Nylén, D.; Holmström, J. Digital innovation strategy: A framework for diagnosing and improving digital product and service innovation. Bus. Horiz. 2015, 58, 57-67. [CrossRef]

18. Schallmo, D.; Williams, C.A. Digital Transformation of Business Models-Best Practices, Enablers and Roadmap. Presented at The XXVIII ISPIM Innovation Conference-Composing the Innovation Symphony, Vienna, Austria, 18-21 June 2017.

19. Bowersox, D.J.; Closs, D.J.; Drayer, R.W. The digital transformation: Technology and beyond. Supply Chain Manag. Rev. 2005, 9, 22-29.

20. Mazzone, D.M. Digital or Death: Digital Transformation: The Only Choice for Business to Survive Smash and Conquer; Smashbox Consulting Inc.: Mississauga, ON, Canada, 2014.

21. Boueé, C.; Schaible, S. Die Digitale Transformation der Industrie; Roland Berger/BDI Studien: Berlin/Munchen, Germany, 2015.

22. Kotarba, M. Digital transformation of business models. Found. Manag. 2018, 10, 123-142. [CrossRef]

23. Sousa, M.J.; Rocha, Á. Digital learning: Developing skills for digital transformation of organizations. Future Gener. Comput. Syst. 2019, 91, 327-334. [CrossRef]

24. Galindo-Martín, M.Á.; Castaño-Martínez, M.S.; Méndez-Picazo, M.T. Digital transformation, digital dividends and entrepreneurship: A quantitative analysis. J. Bus. Res. 2018, 101, 522-527. [CrossRef]

25. Warner, K.S.R.; Wäger, M. Building dynamic capabilities for digital transformation: An ongoing process of strategic renewal. Long Range Plan. 2019, 52, 326-349. [CrossRef]

26. Lam, C.; Law, R. Readiness of upscale and luxury-branded hotels for digital transformation. Int. J. Hosp. Manag. 2019, 79, 60-69. [CrossRef]

27. Zaharia, S.E.; Pietreanu, C.V. Challenges in airport digital transformation. Transp. Res. Procedia 2018, 35, 90-99. [CrossRef]

28. Dengler, K.; Matthes, B. The impacts of digital transformation on the labour market: Substitution potentials of occupations in Germany. Technol. Forecast. Soc. Chang. 2018, 137, 304-316. [CrossRef]

29. Troshani, I.; Janssen, M.; Lymerc, A.; Parker, L.D. Digital transformation of business-to-government reporting: An institutional work perspective. Int. J. Account. Inf. Syst. 2018, 31, 17-36. [CrossRef]

30. von Leipzig, T.; Gamp, M.; Manz, D.; Schöttle, K.; Ohlhausen, P.; Oosthuizen, G.; Palm, D.; von Leipzig, K. Initialising customer-orientated digital transformation in enterprises. Procedia Manuf. 2017, 8, 517-524. [CrossRef]

31. Goerzig, D.; Bauernhansl, T. Enterprise architectures for the digital transformation in small and medium-sized enterprises. Procedia CIRP 2018, 67, 540-545. [CrossRef]

32. Reinartz, W.; Wiegand, N.; Imschloss, M. The impact of digital transformation on the retailing value chain. Int. J. Res. Mark. 2019, 36, 350-366. [CrossRef]

33. Frank, A.G.; Mendes, G.H.S.; Ayala, N.F.; Ghezzi, A. Servitization and Industry 4.0 convergence in the digital transformation of product firms: A business model innovation perspective. Technol. Forecast. Soc. Chang. 2019, 141, 341-351. [CrossRef]

34. Issa, A.; Hatiboglu, B.; Bildstein, A.; Bauernhansl, T. Industrie 4.0 roadmap: Framework for digital transformation based on the concepts of capability maturity and alignment. Procedia CIRP 2018, 72, 973-978. [CrossRef] 
35. Bondar, S.; Hsu, J.C.; Pfouga, A.; Stjepandić, J. Agile digital transformation of System-of-Systems architecture models using Zachman framework. J. Ind. Inf. Integr. 2017, 7. [CrossRef]

36. Jabłoński, A.; Jabłoński, M. Social Business Models in the Digital Economy. New Concepts and Contemporary Challenges; Palgrave Macmillan; Springer Nature Switzerland: Cham, Switzerland, 2020.

37. Jabłoński, A.; Jabłoński, M. Digital Business Models. Perspectives on Modetisation; Routledge: London, UK; New York, NY, USA, 2021.

38. Dohrmann, S.; Raith, M.; Siebold, N. Monetizing Social Value Creation-A Business Model Approach. Entrep. Res. J. 2015, 5, 127-154. [CrossRef]

39. Bhatt, G.D.; Emdad, A.F. An analysis of the virtual value chain in electronic commerce. Logist. Inf. Manag. 2001, 14, 78-85. [CrossRef]

40. Jabłoński, M. Value Migration to the Sustainable Business Models of Digital Economy Companies on the Capital Market. Sustainability 2018, 10, 3113. [CrossRef]

41. Jabłoński, M. The Critical Aspects of Value Migration from Volatile Business Models in the Digital Economy. J. Creat. Value 2019, 5, 1-14. [CrossRef]

42. Jabłoński, A.; Jabłoński, M. Research on Business Models in their Life Cycle. Sustainability 2016, 8, 430. [CrossRef]

43. Jabłoński, M. Determinants of Sustainable Business Model of Companies Early Stage of Development. In Sustainable Business, Management, and Economics WSF; Berger, L., Bergman, M.M., Eds.; MDPI: Basel, Switzerland, 2017; Volume 2. [CrossRef]

44. Jabłoński, A. Scalability of Sustainable Business Models in Hybrid Organizations. Sustainability 2016, 8, 194. [CrossRef]

45. Kożuch, B.; Jabłoński, A. The Strategic Hybrids of Water Supply Companies as an Effective Management Tool. Sustainability 2018, 10, 4450. [CrossRef]

46. Jabłoński, M. The assumptions of Hybrid Business Models based on the concepts of Big Data and the Sharing Economy. In Hybridization in Network Management; Jabłoński, A., Ed.; Nova Science Publishers Inc.: New York, NY, USA, 2019; pp. 2-19.

47. Redondo, T. The Digital Economy: Social Interaction Technologies-An Overview. Int. J. Artif. Intell. Interact. Multimed. 2015, 3, 17-25. [CrossRef]

48. Spieth, P.; Schneider, S.; Clauß, T.; Eichenberg, D. Value drivers of social businesses: A business model perspective. Long Range Plan. 2019, 52, 427-444. [CrossRef]

49. Rao-Nicholson, R.; Vorley, T.; Khan, Z. Social innovation in emerging economies: A national systems of innovation based approach. Technol. Forecast. Soc. Chang. 2017, 121, 228-237. [CrossRef]

50. Fakrulhazri, N.; Hassan, N.; Che Hamid, A.; Fazlin Hiryati, N.; Jaafar, N.; Ahmad, N.; Mekar, U.T. The Knowledge Transfer Program vs. Social Business Model: The Rural Youth Fertigation Project in Dungun. Presented at the Terengganu International Business and Economics Conference 2016 (TiBÉC V), Kuala Terengganu, Malaysia, 22-23 September 2016.

51. Sparviero, S. The Case for a Socially Oriented Business Model Canvas: The Social Enterprise Model Canvas. J. Soc. Entrep. 2019, 10, 232-251. [CrossRef]

52. Ozkan, T.; Yanginlar, G.; Kalayci, S. Railway Transport Liberalization: A Case Study of Various Countries in the World. J. Manag. Sustain. 2016, 6. [CrossRef]

53. Nakano, H. A study on the features of the evolution processes and business models of global enterprises in the transport sector. Transp. Res. Procedia 2017, 25, 3773-3792. [CrossRef]

54. Nikitinas, V.; Dailydka, S. The Models of Management of Railway Companies in the European Union: Holding, the German Experience. Procedia Eng. 2016, 134, 80-88. [CrossRef]

55. Khayyam, S.; Pilo De La Fuente, E.; Bagliano, V.; Huang, Z.; Gonzalez, I.; Monti, A. Evolution of Business Model in Railway Industry in the Presence of Energy Management System; CIRED Workshop: Helsinki, Finland, 2016; p. 0471. [CrossRef]

56. Lovell, K.; Nightingale, P. Business models in rail infrastructure: Explaining innovation. In Proceedings of the Institution of Civil Engineers_Transport; Thomas Telford Ltd.: London, UK, 2016; Volume 169, pp. 262-271.

57. Ovchynnikova, V.; Kuzmenko, A.; Yusupova, T.; Toropova, V.; Gontar, N. Digital Transformation of Innovative Business Processes on Railway Transport. SHS Web Conf. 2019, 67, 01009. [CrossRef]

58. Sousa, M.J.; Rocha, Á. Skills for disruptive digital business. J. Bus. Res. 2019, 94, 257-263. [CrossRef] 
59. König, M.; Ungerer, C.; Baltes, G.; Terzidis, O. Different patterns in the evolution of digital and non-digital ventures' business models. Technol. Forecast. Soc. Chang. 2018, 146, 844-852. [CrossRef]

60. Schmidt, R.; Möhring, M.; Härting, R.C.; Reichstein, C.; Neumaier, P.; Jozinović, P. Industry 4.0-Potentials for Creating Smart Products: Empirical Research results. In International Conference on Business Information Systems; Springer: Cham, Switzerland, 2015; pp. 16-27. [CrossRef]

61. Härting, R.C.; Reichstein, C.; Schad, M. Potential of digital business models-Empirical investigation of data driven impacts in industry. Procedia Comput. Sci. 2018, 126, 1495-1506. [CrossRef]

62. Community of European Railway and Infrastructure Companies (CER). A Roadmap for Digital Railways; The Voice of European Railways CER: Warszawa, Belgium, 2018.

63. Pieriegud, J. Raport-Transformacja Cyfrowa Kolei, Szkoła Główna Handlowa, Siemens Sp. z o.o.; Fundacja ProKolej: Warszawa, Poland, 2017.

64. Digital Railway Development. Making Rail Smarter, 4th ed.; International Union of Railways (UIC): Paris, France, 2017.

65. Sklyar, A.; Kowalkowski, C.; Tronvoll, B.; Sörhammar, D. Organizing for digital servitization: A service ecosystem perspective. J. Bus. Res. 2019, 104, 450-460. [CrossRef]

66. Kowalkowski, C.; Gebauer, H.; Kamp, B.; Parry, G. Servitization and deservitization: Overview, concepts, and definitions. Ind. Mark. Manag. 2017, 60,4-10. [CrossRef]

67. Mastrogiacomo, L.; Barravecchia, F.; Franceschini, F. Definition of a conceptual scale of servitization: Proposal and preliminary results. CIRP J. Manuf. Sci. Technol. 2020, 29, 141-156. [CrossRef]

68. Palo, T.; Åkesson, M.; Löfberg, N. Servitization as business model contestation: A practice approach. J. Bus. Res. 2019, 104, 486-496. [CrossRef]

69. Cenamor, J.; Sjödin, D.R.; Parida, V. Adopting a platform approach in servitization: Leveraging the value of Digitalization. Int. J. Prod. Econ. 2017, 192, 54-65. [CrossRef]

70. Reim, W.; Sjödin, D.R.; Parida, V. Servitization of global service network actors-A contingency framework for matching challenges and strategies in service transition. J. Bus. Res. 2019, 104, 461-471. [CrossRef]

71. Hullova, D.; Laczko, P.; Frishammar, J. Independent distributors in servitization: An assessment of key internal and ecosystem-related problems. J. Bus. Res. 2019, 104, 422-437. [CrossRef]

72. Scott, J. What Is Social Network Analysis? Bloomsbury Publishing: London, UK; New York, NY, USA, 2012.

73. Verhoef, P.C.; Broekhuizen, T.; Bart, Y.; Bhattacharya, A.; Qi Dong, J.; Fabian, N.; Haenlein, M. Digital transformation: A multidisciplinary reflection and research agenda. J. Bus. Res. 2021, 122, 889-901. [CrossRef]

74. Wolf, W. Cyber-physical Systems. Computer 2009, 42, 88-89. [CrossRef]

75. Marrone, S.; Rodríguez, R.J.; Nardone, R.; Flammini, F.; Vittorini, V. On synergies of cyber and physical security modeling in vulnerability assessment of railway systems. Comput. Electr. Eng. 2015, 47, 275-285. [CrossRef]

76. Śliwiński, M.; Piesik, E.; Piesik, J. Integrated functional safety and cyber security analysis. IFAC-PapersOnLine 2018, 51, 1263-1270. [CrossRef]

77. Collis, J.; Hussey, R. Business Research; Palgrave Macmillan: New York, NY, USA, 2003.

Publisher's Note: MDPI stays neutral with regard to jurisdictional claims in published maps and institutional affiliations.

(C) 2020 by the authors. Licensee MDPI, Basel, Switzerland. This article is an open access article distributed under the terms and conditions of the Creative Commons Attribution (CC BY) license (http://creativecommons.org/licenses/by/4.0/). 